\title{
Research on Optimization of Financial Management in Big Data Era
}

\author{
Wang Hongni, Dongying Vocational College, Dongying, Shandong, 257091
}

\begin{abstract}
Twenty-first century is a rapid development century of science and technology, and will also be an era of big data. The enterprises should follow the big data era footsteps in the financial management in order to succeed in the fierce competition. Firstly, the article analyses the concept of the era of big data and then gives the applications of big data in the financial management optimization. Finally, the article puts forward several methods to improvethe level of usingbig data of enterprises.
\end{abstract}

KEYWORDS:financial management; big data era

\section{INTRODUCTION}

Big data is a relatively abstract concept. Currently, the definition of the concept of big data is not uniform. Schonberg known as the "the first man who apply big data in business" points out that the "big" in big data does not refer to the absolute number but the processing mode. We will try to collect comprehensive data, complete data and synthetic data, at the same time, the use of mathematical methods to analyze and its modeling, mining behind the relationship, thus predicting the probability of event happening behind. The world famous management consulting company McKinsey's big data is defined as the data which cannot use traditional database software tools in a certain period of time, the contents of the acquisition management and processing of data set. The most representative definition of many big data definitions is the $3 \mathrm{~V}$ definition. The first $\mathrm{V}$ means volume, namely the data volume is huge; the second $\mathrm{V}$ means variety, namely there are a lot of data types in big data, such as text, images, audio, video and so on; The third $\mathrm{V}$ means volume velocity, that is the fast processing speed of big data. In addition, International Data Corporation (IDC) believes that big data should also have the high commercial value. IBM believes big data should be veracity. In short, the definition of big data concept can be based on $3 \mathrm{~V}$ or $4 \mathrm{~V}$ or $5 \mathrm{~V}$.

Data is expanding rapidly and becomes larger. It determines the future development of enterprises.Although many enterprises may not realize it, people will be more awareness of the importance of the big data of enterpriseswith the passage of time. As New York Timessaid in 2012, big data era has come. In the commercial, economic and other fields, the decision will be increasingly based on big data rather than experience and intuition.

\section{Optimization of Financial Management in Big Data Era}

Finance management needs the data most in the related professionals in the field of enterprise management. At the same time, the most comprehensive information fusion of the financial sector is also the enterprise department. Effect of big data on finance will be far-reaching. If data is the enterprise uses the well it, it will urge enterprises to improve the status of financial department in the company, the financial influence on corporate strategy will improve faster with big data technologies, financial managers can effectively improve the level of financial management, the compression 
cost of capital, bring rich profit for the enterprise. Based on this, big data provides valuable opportunities for the financial management.

\section{A: Reduce Operation Cost}

All kinds of financial information of enterprises can be brought by enterprise big data. Business leaders can get the enterprise interior various departments work state, capable of performing internal better organization of enterprise resources work to improve the utilization rate of resources, make the enterprise operation more scientific and efficient, so as to reduce the running cost of the enterprise. Big data and enterprise can be collected timely manufacturing costs associated with various types of data, and these data used in the enterprise cost control system, through the scientific collection and distribution, it can more accurately calculate the cost, thus effectively into the control to provide the scientific basis for decision making of enterprises. At the same time, big data technology helps us to realize the proper distribution of financial data and non-financial resources and provide a scientific and overall budget.

\section{B: Measure Fair Value}

Accounting estimate is a judgment based on the results of the latest information of transaction and uncertainty. Fair value is obtained according to the measurement object environment in ensuring reliable information under the premise, as far as possible by the method of minimum cost to get enough information, in order to increase reliability. The age of big data provides data source of information and communication channels are widely diverse for the accountant data, along with the openness of the continuous improvement. The accounting staff will use the data source to make more accurate accounting estimates and fair valuemore smooth and precise.

\section{C: Distinguish False Information}

Handling all kinds of reimbursement of enterprises is a basic financial job. It is difficult to distinguish the truth of the notes. But in the age of big data, with flights, ticket, rent and other information can make judgments on bill authenticity. According to the current situation, the development of government continue to support data, coupled with the mobile equipment data transmission of epidemic, brought continuously find new consumer groups, business opportunities for enterprises. The enterprise must to seize the business opportunities, through the analysis of the data has been mastered information, for the enterprise to discover and select products market, the consumer level and provide the basis for consumer demand. In big data analysis pay attention to discover potential competitors and clear investigation background, price and advantage of competitors and other key information to screening and treatment process. The enterprises must make corresponding measures to seize more market share to achieve the final victory.

\section{D: Improve Enterprise Marketing}

The old market survey of enterprises has the problems of poor timeliness. The customer data obtained is generally outdated and is unable to provide more effective data security. Therefore, enterprises must establish a strong timeliness of dynamic data system, based on the dynamic data analysis and processing of the more deep determine the enterprise needs to overcome the target customers. According to the consumer demand, enterprisescan improve service to guide consumer's consumption habits. 


\section{Raise the Level of Applications of Big Data in Financial Management}

\section{A: Raise Data Awareness}

On one hand, the traditional data analysis for enterprise decision-making layer is not new which relies on the "almost" or "maybe" data to make decisions. On the other hand, the benefit of using the high cost of big data processing tool is difficult to accurately quantify.These factors inevitably draw a gap between big data and enterprise decision. But must realize is, since ancient times, there has never been a time appeared so big data explosion. If the enterprise cannot be aware of this change, can quickly identify from the data in the risk and explore business opportunities, in the future competition in the industry will inevitably be gradually defeated, reduced to the bottom of the chain business. Enterprise ideology update, the biggest driving force than the decision layer determination. Only the big data management awareness of decision-makers of enterprises is built, the enterprise big data consciousness will be set up fundamentally.

\section{B: UpgradeSoftware Module}

The age of big data is not just a variety of numbers, letters and simple code. It also includes a variety of image, voice, web logs and other. We must vigorously strengthen the function module of existing financial management software upgrade in order to effectively extract such variety and huge data information used for financial management work. First of all, to strengthen the processing of various shaped data extraction function, such as the picture, sound, text of information classification and code conversion and convenient management and extraction, secondly also financial data keyword search engine development, improve the efficiency of screening of effective information.
Simultaneously, we should also further input port management of all kinds of data information source and vigorously enhance the data informationefficiency and quality.

\section{C: Establish Specialized Agencies}

We should separate the financial management from the accounting department.

Financial management of the establishment is equipped with full competence of practitioners. Management on financial data is the core of all the business data. In the age of big data, like the funds, land and intellectual property, the business data also belongs to the core of the enterprise financial resources. It is unique, the business enterprise management not only the amount of data can be huge, updated quickly, at the same time also is the variety of. But no matter how many links through, these data will eventually be reflected in the financial data by some form of. Therefore, by financial personnel in charge of business data has a natural advantage. Shared service center or financial outsourcing by financial liberation way, is entirely possible to be a large number of experienced financial personnel from the complicated accounting work, it also showed the feasibility by financial personnel in charge of the business data. At the same time, we must also see the limitations of their own financial personnel with appropriate proportion in institutions. The appropriateproportion of non-financial personnel in financial management is also important.

\section{D: Build Assessment Mechanism}

Although the financial management result can be qualitatively identified, it is difficult to quantitative assessment. The scientific performance appraisal system is very important. Scientific performance appraisal system cannot combat the financial management personnel's enthusiasm, also cannot exaggerate its 
contribution. At the same time, should conscientiously do a good job in the internal audit work of financial management, the authenticity of the focus on business data, timely find defects of big data management system and its continuous correction. The level of the management team quality and management quality has very close links. The group enterprise financial management team's quality has been improved significantly, but in big data context to strengthen knowledge of technical mastery and further enhance the level of. So we should strengthen the quality cultivation mode of management personnel selection to provide professional and standardmanagement personnel to enterprises.

\section{Conclusions}

The big data era provides a good opportunity to promote the enterprise financial transformation. The big data can reduceoperation cost, measure fair value, distinguish false information and improve enterprise marketing. We should raise data awareness, upgrade software module, establish specialized agencies and build assessment mechanismto reform financial management.

\section{REFERENCE:}

[1] Shuang Yang, Kun guo. Framework Formation of Financial Data Classification Standard in the Era of the Big Data[J] Procedia Computer Science, 2014,30

[2] Edward W. Sun. Generalized optimal wavelet decomposing algorithm for big financial data

[J] International Journal of Production Economics, 2013, 01

[3] Fan Wenfei, Huai Jinpeng. Querying Big Data: Bridging Theory and Practice [J] Journal of Computer Science \& Technology, 2014, 05 